\title{
Recombinant Factor VIII Concentrates
}

\author{
Massimo Franchini, M.D., ${ }^{1}$ and Giuseppe Lippi, M.D. ${ }^{2}$
}

The authors regret the inclusion of some errors in the above mentioned review article published in Seminars in Thrombosis and Hemostasis, volume 36, number 5, pages 493 to 497. ${ }^{1}$ The errors were brought to the authors' attention by a manufacturer of one of the products mentioned. While all the observations made by this manufacturer are pertinent, the authors would also like to point out that the differences in the manufacturing processes of the recombinant factor VIII (FVIII) concentrates are particularly complex, and that there is great confusion in the literature regarding the virus-inactivation/-purification steps used for the different products. For instance, in recent reviews by Frampton and Wagstaff, ${ }^{2}$ and by Pipe, ${ }^{3}$ it is stated that the second generation recombinant FVIII ReFacto contains a nanofiltration step. This is incorrect, because this process is unique for the third generation Refacto AF/Xyntha. ${ }^{4,5}$ Thus, we believe that the only way to have accurate information on the manufacturing processes of $\mathrm{rFVIII}$ concentrates is through direct consultation of the technical characteristics of the products released by the manufacturer.

The specific corrections in relation to our review article $^{1}$ are the following:

1. Table 1, page 494. Methods of Purification/viral reduction of ReFacto: "Filtration/IA/ IE/SD" is replaced with "IA/IE/SD". Methods of Purification/viral reduction of Kogenate FS: "IA/IE/SD" is replaced with "IA/IE/SD/U". Methods of Purification/ viral reduction of Xyntha: "IA/IE/SD" is replaced with "IA/IE/SD/N" (see Table 1)." . Table 1, page 494. Methods of Purification/viral reduction of ReFacto: "Filtration/IA/ IE/SD" is replaced with "IA/IE/SD". Methods of Purification/viral reduction of Kogenate FS: "IA/IE/SD" is replaced with "IA/IE/SD/U”. Methods of Purification/ viral reduction of Xyntha: "IA/IE/SD" is replaced with "IA/IE/SD/N" (see Table 1)."

2. Page 494, first column: The sentence "Finally, third-generation rFVIII products (ADVATE [Baxter Healthcare, Westlake Village, CA] and Xyntha [Wyeth Pharmaceuticals, Philadelphia, PA]), which are devoid of any additional animal and human protein within both the cell culture and the final formulation, have been licensed since 2003," should be replaced by "Finally, the third-generation rFVIII products ADVATE (Baxter Healthcare) and Xyntha (Wyeth Pharmaceuticals), which are devoid of any additional animal and human protein within both the cell culture and the final formulation, have been licensed since 2003 and 2008, respectively.”

${ }^{1}$ Servizio di Immunoematologia e Medicina Trasfusionale, Dipartimento di Patologia e Medicina di Laboratorio, Azienda Ospedaliero-Universitaria di Parma; ${ }^{2}$ U.O. di Diagnostica Ematochimica, Dipartimento di Patologia e Medicina di Laboratorio, Azienda Ospedaliero-Universitaria di Parma, Parma, Italy.

Address for correspondence and reprint requests: Massimo Franchini, M.D., Servizio di Immunoematologia e Trasfusione, Azienda Ospedaliero-Universitaria di Parma, Parma, Italy (e-mail: massimo.franchini@azosp.vr.it).

Microparticles in Thrombosis and Hemostasis; Guest Editors, Nigel S. Key, M.D., and Hau C. Kwaan, M.D., Ph.D.

Semin Thromb Hemost 2010;36:930-932. Copyright (C) 2010 by Thieme Medical Publishers, Inc., 333 Seventh Avenue, New York, NY 10001, USA. Tel: +1(212) 584-4662.

DOI: http://dx.doi.org/10.1055/s-0030-1267777.

ISSN 0094-6176. 
Table 1 Main Characteristics of Licensed rFVIII Concentrates

\begin{tabular}{|c|c|c|c|c|c|c|c|}
\hline rFVIII Product & Manufacturer & Generation & $\begin{array}{l}\text { Host Cell } \\
\text { Line }\end{array}$ & $\begin{array}{l}\text { FVIII } \\
\text { Molecule }\end{array}$ & CMA & FVIII Stabilizer & $\begin{array}{l}\text { Purification/ } \\
\text { Viral/Reduction }\end{array}$ \\
\hline Recombinate & Baxter Healthcare & First & $\mathrm{CHO}$ & Full length & $\mathrm{BI}, \mathrm{BA}, \mathrm{BSA}$ & Human albumin & $\mathrm{IA} / \mathrm{IE}$ \\
\hline Kogenate FS* & Bayer Healthcare & Second & $\mathrm{BHK}$ & Full length & HSA & Sucrose & IA/IE/SD/U \\
\hline ReFacto & Wyeth Pharmaceuticals & Second & $\mathrm{CHO}$ & BDD & HSA & Sucrose & IA/IE/SD \\
\hline ADVATE & Baxter Healthcare & Third & $\mathrm{CHO}$ & Full length & None & Trehalose & IA/IE/SD \\
\hline
\end{tabular}

* Kogenate Bayer in Europe. Also marketed as Helixate FS (Helixate NexGen in Europe) by CSL Behring

'ReFacto AF in Europe.

rFVIII, recombinant factor VIII; CMA, culture medium additives (human or animal); BI, bovine insulin; BA, bovine aprotinin; BSA, bovine serum albumin; HAS, human serum albumin; $\mathrm{CHO}$, Chinese hamster ovary; BHK, baby hamster kidney; IA, immunoaffinity; IE, ion exchange; SD, solvent/detergent treatment; BDD, B-domain-deleted; U, ultrafiltration; N, nanofiltration.

3. Page 494, second column: The following statement is incorrect and should be replaced with the one in the next paragraph: "The production of second generation products also is based on solvent/detergent and either ultra- or nano-filtration to reduce transmission of enveloped (i.e., human immunodeficiency virus [HIV], hepatitis B virus [HBV] and hepatitis $\mathrm{C}$ virus $[\mathrm{HCV}]$ ) and non-enveloped viruses (i.e., hepatitis $\mathrm{A}$ virus and parvovirus B19) ${ }^{13,14}$ For instance, solvent/detergent and ultrafiltration are used for Kogenate FS, whereas solvent/detergent and nanofiltration are used for ReFacto. Similar techniques are employed for the production of third-generation rFVIII concentrates (solvent/detergent for Xyntha, solvent/detergent and nanofiltration for ADVATE).”

The correct statement is: "The production of second and third generation products also is based on solvent/detergent and filtration to reduce transmission of enveloped (i.e., human immunodeficiency virus $[\mathrm{HIV}]$, hepatitis $\mathrm{B}$ virus $[\mathrm{HBV}]$ and hepatitis $\mathrm{C}$ virus $[\mathrm{HCV}]$ ) and non-enveloped viruses (i.e., hepatitis $\mathrm{A}$ virus and parvovirus B19). ${ }^{13,14}$ For instance, solvent/detergent and ultrafiltration are used for the second generation rFVIII Kogenate FS, whereas solvent/detergent and nanofiltration are used for the third generation rFVIII Xyntha (or ReFacto AF in Europe)."

4. Page 495, first column: "Kogenate AF" should be replaced with "Kogenate FS."

\section{REFERENCES}

1. Franchini M, Lippi G. Recombinant factor VIII concentrates. Semin Thromb Hemost 2010;36(5):493-497

2. Frampton JE, Wagstaff AJ. Sucrose-formulated octocog alfa: a review of its use in patients with haemophilia A. Drugs 2008; 68(6):839-853

3. Pipe SW. Recombinant clotting factors. Thromb Haemost 2008;99(5):840-850
4. Eriksson RK, Fenge C, Lindner-Olsson E, et al. The manufacturing process for B-domain deleted recombinant factor VIII. Semin Hematol 2001;38(2, Suppl 4): 24-31

5. Kelley B, Jankowski M, Booth J. An improved manufacturing process for Xyntha/ReFacto AF. Haemophilia 2010;16(5): $717-725$ 